\title{
Nice Figueiredo, Momento Feminino e o debate feminista no Brasil
}

\author{
Iracélli da Cruz Alves*
}

\begin{abstract}
RESUMO
No artigo, nossa intenção é analisar parte do discurso da advogada feminista Nice Figueiredo, constante no jornal Momento Feminino, organizado e dirigido por mulheres ligadas ao Partido Comunista Brasileiro (PCB). Nice Figueiredo foi responsável pela coluna "Direitos da Mulher" de 1947 até 1950. Na oportunidade, publicou artigos em defesa da modificação do Código Civil brasileiro vigente no período, que restringia os direitos das mulheres casadas, especialmente no campo do trabalho remunerado. Ao reivindicar mais liberdades para as mulheres, especialmente as casadas, a advogada criticou os padrões socioculturais de gênero, pondo em xeque naturalizações correntes sobre a masculinidade e a feminilidade. As linhas que seguem, tem como finalidade demonstrar as reflexões feministas de Nice Figueiredo entre 1947 e 1949, período em que sua atuação como colunista foi mais expressiva. Não deixaremos de apontar os pontos de tensão com o editorial de Momento Feminino. A análise é parte de uma reflexão mais ampla desenvolvida na pesquisa de doutoramento cujo objetivo principal é evidenciar, principalmente a partir do movimento desenvolvido pelas mulheres do $\mathrm{PCB}$, a atuação feminista no Brasil antes da década de 1970, conhecida como a década do feminismo.
\end{abstract}

Palavras-chave: Nice Figueiredo. Momento Feminino. Feminismo.

\section{Nice Figueiredo, Momento Feminino and the feminist debate in Brazil}

\begin{abstract}
In the article, our intention is to analyze part of the discourse of the feminist lawyer Nice Figueiredo, included in the newspaper Momento Feminino, organized and directed by women linked to the Brazilian Communist Party (PCB). Nice Figueiredo was responsible for the column entitled "Women's Rights" from 1947 to 1950. At the time, she published articles in defense of the modification of the Brazilian Civil Code in force in the period, which restricted the rights of married women, especially in the field of paid work. By calling for more freedoms for women, especially married women, the lawyer criticized sociocultural gender patterns, calling into question current naturalizations about masculinity and femininity. The following lines, have as purpose to demonstrate the feminist reflections of Nice Figueiredo between 1947 and 1949, period in which its performance like columnist was more expressive. We will not fail to point out the tension points with the editorial of Momento Feminino. The analysis is part of a broader reflection developed in the doctoral research whose main objective is to highlight, mainly from
\end{abstract}

\footnotetext{
* Doutoranda no Programa de Pós-Graduação em História da Universidade Federal Fluminense, sob a orientação de Rachel Soihet. Mestra em História pela Universidade Estadual de Feira de Santana e graduada em Licenciatura Plena em História pela Universidade do Estado da Bahia, campus II. O presente trabalho foi realizado com apoio da Coordenação de Aperfeiçoamento de Pessoal de Nível Superior - Brasil (CAPES) - Código de Financiamento 001. Email: iracelli_alves@hotmail.com.
} 
the movement developed by the PCB women, the feminist performance in Brazil before the 1970s, known as the decade of feminism.

Keywords: Nice Figueiredo. Momento Feminino. Feminism.

Artigo recebido em 10 fev. 2019.

Artigo aceito em 8 jun. 2019

Sexta-feira, 25 de julho de 1947; saía nas bancas a primeira edição do semanário Momento Feminino, periódico "fundado, dirigido e redigido por mulheres" (Diário de Notícias, 12/08/1947, p. 3, seção 2). O subtítulo - "um jornal para seu lar" - indicava que mais uma revista direcionada aos "assuntos femininos" estava saindo do forno. Em suas páginas o público encontraria dicas de beleza, maternidade, cuidados com o lar, corte e costura entre outros temas comuns aos periódicos para mulheres. No entanto, foi além das prendas domésticas e dicas de beleza, assumindo a tarefa de contribuir com a formação política das leitoras. Circulou até 1956 com uma regularidade variável. Até janeiro de 1948 foi às ruas semanalmente. Em 1949 tornouse mensal, com quebras de regularidade. Em momentos especiais, saía mais de uma vez por mês, outras vezes ficava mais tempo fora de circulação. ${ }^{1}$ No ano seguinte as publicações tornaram-se ainda mais irregulares, mas circulou, no mínimo, uma vez por mês. A partir de 1952 as dificuldades de colocá-lo nas ruas tornaram-se mais aparentes. ${ }^{2}$ Em alguns momentos foi preciso reduzir o número de publicações e, às vezes, o número de páginas. Nos dois últimos anos não conseguimos precisar a regularidade, em função dos limites do próprio arquivo, que aparentemente não armazena alguns números. ${ }^{3}$ Normalmente, possuía de 8 a 10 páginas em tamanho tabloide. ${ }^{4}$ Era estruturado como uma revista. Possuía uma capa com grandes imagens (desenhos ou fotografias) ou poemas em homenagem às mulheres e crianças. ${ }^{5}$

A iniciativa de fundar o jornal partiu de mulheres ligadas ao Partido Comunista do Brasil - que mais tarde, em 1961, passou a se chamar Partido Comunista Brasileiro (PCB). No entanto, entre suas colaboradoras havia mulheres de outras correntes políticas, a exemplo de Lygia Maria de Lessa Bastos, à época, vereadora do Distrito Federal pela União Democrática Nacional (UDN); Sagramor de Scuvero, então vereadora pela Partido Republicano (PR) e Alice Tibiriçá (1886-1950), que não tinha filiação partidária, mas já vinha atuando na política pública através do movimento feminista desde a década de 1920. Em 1922, Alice foi uma das fundadoras da Federação Brasileira pelo Progresso Feminino. ${ }^{6}$ Mas a diretoria era praticamente toda pecebista. A direção geral coube a Arcelina Mochel (1918-1974), que entre 1946 e 1948 também atuou como vereadora do Rio de Janeiro pelo PCB. Incialmente, os demais cargos foram ocupados 
por pecebistas: diretora-chefe, Lia Correa Dutra (1908-1989); secretária, Silvia Leon Chalreo (1905-1991); redatoras, Eneida Costa de Moraes (1903-1971) e Maura de Sena Pereira (19041991); gerente, Heloísa Ramos (1910-1999). Glória Cordeiro de Andrade assumiu a chefia de publicidade. Não sabemos se ela era filiada ao PCB, mas muito provavelmente mantinha algum envolvimento, já que praticamente toda a diretoria era comunista. ${ }^{7}$

Vinculado a um partido politicamente estigmatizado em função do anticomunismo ${ }^{8}$, Momento Feminino se empenhou, não sem tensões e contradições, em imbricar a luta pela emancipação das mulheres à luta de classes. Para tanto, construiu algumas alternativas; uma delas foi a coluna "Direitos da Mulher", cuja responsabilidade, até junho de 1950, coube a advogada Nice Figueiredo, que se dedicou a combater as desigualdades entre homens $e$ mulheres no mundo do trabalho, nas relações familiares e no campo da moral sexual; todas elas ratificadas na esfera jurídica.

O Código-Civil de 1916 foi resultado de muitas tentativas de fornecer ao Brasil um conjunto de leis civis que substituíram a legislação portuguesa que ainda vigorava no país. A autoria de sua primeira versão coube ao jurista Clóvis Bevilácqua, que apresentou o projeto em 1899, sendo aprovado apenas em 1916. O Código era bastante restritivo no que diz respeito à cidadania das mulheres casadas. Estabelecia às esposas o lugar de pessoas jurídicas relativamente incapazes e ao marido a chefia da família. Ele tinha o dever de proteger, defender e sustentar financeiramente esposa e filhos, enquanto elas eram proibidas, entre outras coisas, de aceitar herança ou ter um emprego sem sua autorização, que poderia, a qualquer momento, desautorizá-la. Também impunha desigualdade de poder entre pai e mãe, pois às mães não era dado o pátrio-poder, atribuído apenas ao pai. Somente em 27 de agosto de 1962, após três décadas de intensos debates, o Código-Civil passou por sua primeira reformulação, mas manteve o homem como chefe da família e exclusivamente responsável pela administração dos bens comuns, seu ponto mais conservador; no entanto, liberou a mulher que desejasse ter uma profissão da tutela do marido (Marques; Melo, 2008). ${ }^{9}$

A advogada Nice Figueiredo, embora pouco conhecida nas narrativas históricas sobre o movimento político em prol de mudanças no Código-Civil, também se engajou no movimento contra as limitações jurídicas que o código impunha às mulheres casadas. Formada pela antiga Faculdade Nacional de Direito da Universidade do Brasil (RJ), além de advogada e colunista do jornal, Nice foi membro do Instituto Feminino de Serviço Construtivo, fundada em 1946. Na instituição, assumiu a diretoria do Departamento dos Direitos da Mulher, cargo que lhe rendeu a participação no II Congresso Internacional de Mulheres, que ocorreu em Budapeste em 1949. Também se enveredou na arte, atuando como atriz na peça Vestir os Nus cujo texto foi escrito 
em 1922 pelo italiano Luigi Pirandelo, prêmio Nobel da Literatura. A peça encenada por Nice foi dirigida por Willy Keller. ${ }^{10}$ Foi colaboradora de Momento Feminino, escrevendo para a coluna "Direitos da Mulher" de setembro de 1947 até junho de 1950. Seu objetivo: "esclarecer as mulheres que querem ser esclarecidas a respeito dos direitos e deveres que têm e que precisam $e$ devem ter, e mostrar-lhes quais as maneiras de garanti-los e conquistá-los" (Momento Feminino, 09/04/1948, p. 5). O espaço se constitui em um meio privilegiado para o debate feminista do período. Ao longo de sua trajetória no periódico publicou 51 artigos, a maioria se direcionou à crítica ao Código-Civil. ${ }^{11}$

Nice Figueiredo denunciou o caráter sociocultural que inferiorizava as mulheres $e$ as impedia do exercício pleno da cidadania, especialmente quando casadas. Ela acreditava que no Brasil e em países cuja legislação era semelhante, o casamento significava para as mulheres "um atestado de retrocesso mental" (Momento Feminino, 20/02/1948, p. 4), já que as limitações que lhes eram impostas após o casamento comprometiam suas atividades em todas as esferas: na família, no trabalho e no poder de gerir seus próprios bens e negócios. Em suma, a mulher era infantilizada na medida em que perdia o direito de autogovernar-se. Valendo-se das ocasiões abertas pelo contexto, a colunista soube aproveitar as brechas para, através da luta por direitos civis para as mulheres, questionar parte dos padrões de feminilidade e masculinidade vigentes. Esteve, inclusive, atenta ao fato de que os ideais de masculinidade eram tóxicas aos homens, especialmente aos da classe trabalhadora. Mas a coluna "Direitos da Mulher", como o próprio nome indica, era direcionada principalmente às mulheres; apresentando-se como um meio de educa-las para a emancipação. Não por acaso, constantemente, Nice demarcava seu lugar de vanguarda na tarefa de "esclarecer as mulheres sobre os problemas do seu interesse para podermos convidá-la a defesa e a conquista dos seus direitos" (Momento Feminino, 27/02/1948, p. 8).

Como advogada, assumiu a tarefa de educadora jurídica, tornando o juridiquês uma linguagem acessível ao público amplo. Escreveu textos sobre os direitos das mulheres na família, no casamento e no mercado de trabalho. A maioria teve como pano de fundo a análise da inferiorização do gênero feminino no plano legal. No entanto, suas orientações não se resumiam a meras descrições dos dispositivos legais. Ao reivindicar mudanças na lei, analisou como as hierarquias entre homens e mulheres eram construídas no âmbito da cultura. Segundo ela, a legislação estava baseada em princípios ligados à tradição $e$ às "mentalidades" construídas a partir de uma divisão de serviços "estabelecida pelos homens" (Momento Feminino, 23/01/1948, p. 8). 
O movimento pela alteração do Código-Civil, no qual o discurso de Nice Figueiredo estava sintonizado, relacionava-se ao processo de mudanças socioculturais pelas quais o Brasil passava. O período compreendido entre o final do século XIX e os primeiros anos do XX foi marcado por transformações socioculturais e pela inclusão de novas demandas sociais. De acordo com Durval Muniz de Albuquerque Junior (2013), o advento da República proporcionou um progressivo acesso ao mundo da política de sujeitos antes excluídos, tais como, comerciantes, industriais, operários e, notadamente, as mulheres. Iniciou-se uma "perda progressiva dos valores, sociabilidades e sensibilidades descritas como patriarcais" (Albuquerque Júnior, 2013, p. 30). A educação urbana das novas gerações das elites promoveu mutações subjetivas, provocando uma progressiva dissenção em relação aos valores e costumes predominantes na sociedade agrária e escravocrata. Entre os valores que passaram a ser questionados estavam os de obediência cega aos pais e de aceitação da realização de uniões conjugais assentadas apenas no interesse econômico e político. Em decorrência de tantas transformações, tanto objetivas quanto subjetivas, tornou-se cada vez mais crescente a preocupação com uma possível quebra das hierarquias de gênero (Albuquerque Júnior, 2013).

Esse era o universo no qual os textos de Nice Figueiredo foram elaborados. Prestes a completar o seu quinquagésimo aniversário, o século XX permanecia operando na dicotomia homem: espaço público; mulher: esfera privada. As mulheres ainda eram socialmente inferiorizadas. Nice Figueiredo se colocou na trincheira, ao lado daquelas que reivindicavam que todas as mulheres tivessem autonomia para decidirem sobre suas próprias vidas e que esse direito fosse legalmente ratificado. Reconhecia que a sociedade estava culturalmente inclinada a aceitar as hierarquias de gênero como naturais, mas mostrava-se otimista frente às mudanças. Sua trajetória como colunista do Momento Feminino foi marcada por tensões internas e com o público leitor. Algumas leitoras se incomodaram com a "radicalidade" do seu discurso. O jornal tentou assumir o lugar de neutralidade diante das polêmicas, justificando que não se responsabilizava "por conceitos emitidos em artigos assinados - é um princípio da ética jornalística. No entanto, estaremos sempre vigilantes para as opiniões que não são recomendáveis" (Momento Feminino, 07/11/1947, p. 12); ao passo que Nice defendeu que os problemas só poderiam ser resolvidos se "encarados de frente, com coragem, sem subterfúgios que conseguiram mantê-los insolúveis até o presente" (Momento Feminino, 14/11/1947, p. 12).

É preciso compreender que assim se orienta esta coluna no esclarecimento que pretende trazer às leitoras sobre os direitos femininos e a lei que os garante ou cerceia. Tendo de ser emitidos, e já foram antes conceitos que estão na mente de cada um de nós, escondidos, sem forças para vir à tona. Terão de ser 
afirmados princípios que contrariam os anteriormente estabelecidos $e$ convenientemente conservados. Mas serão ditos. Porque se cada um de nós mantiver princípios, além de marcar um tento favorável à hipocrisia, estará impedindo, voluntariamente, a solução de problemas sérios como são os da constituição de uma família. Não nos devemos deixar intimidar pelo temor das más interpretações, pois ao lado da saudável "voz do povo" existe sempre a maledicência, fruto da incompreensão sistemática que nada querem ver ou ouvir, mas só falar. Não deveríamos recear sermos incompreendidas, porque há sempre um terreno propício à semente lançada que germina logo que passa o primeiro contato com a terra dura e fria (Momento Feminino, 14/11/1947, p. 12).

Para a advogada, os problemas abordados em seus artigos, especialmente aqueles relacionados à família e às relações matrimoniais, poderiam até ser tratados em "linguagem açucarada dos que dizem as coisas para não serem entendidos" (Momento Feminino, 14/11/1947, p. 12). No entanto, essa não era a sua intenção; ela queria se fazer entender. Portanto, não pretendia mascarar problemas duros com linguagem "açucarada". Não queria "apenas escrever, fazer artigos e sim esclarecer as leitoras sobre os problemas que lhe dizem respeito, sobre os direitos que já têm como mulher, mãe e esposa e, principalmente, sobre os direitos que devem ser conquistados" (Momento Feminino, 14/11/1947, p. 12). Sua utopia era um modelo de família "onde o amor e a solidariedade sejam, de fato, seus alicerces" (Momento Feminino, 14/11/1947, p. 12). Por isso, julgou imprescindível que o problema fosse abordado com uma linguagem franca, que muitas vezes soou dura e/ou radical demais para um jornal que pretendia ter um amplo público de mulheres.

A advogada parecia pouco disposta a abrir mão dos princípios que julgava fundamentais à luta pela libertação das mulheres, por isso, permaneceu denunciando em tom ácido as assimetrias que marcavam as relações de gênero, inclusive no que se refere à moral sexual. Apesar da afinidade política com o corpo editorial de Momento Feminino, ao que tudo indica, Nice manteve uma postura mais independente. A autora chegou, inclusive, a demarcar que muitos dos problemas enfrentados pelas mulheres considerados como "questões de classe" eram, na verdade, "problemas de sexo". Esta interpretação destoava das concepções hegemônicas do $\mathrm{PCB}$, que entendia que as assimetrias sexuais eram consequência das desigualdades de classe. Desse modo, a libertação das mulheres estaria subordinada à conquista do socialismo.

Seu engajamento contra o modelo de casamento então vigente lhe rendeu a pecha de contrária aos laços matrimoniais, ao passo que ela se justificou: "Quem disse que somos contra o casamento? Muito ao contrário. Discordamos até da modinha que diz que a vida de solteiro é 
melhor que a de casado..." (Momento Feminino, 27/02/1948, p. 7). ${ }^{12}$ Mas declarou ser contra o modelo de casamento então praticado e ratificado pela lei civil.

Contra o casamento que diminui e inferioriza a mulher, transformando-a de pessoa plenamente capaz em relativa incapaz, contra o casamento que, a serviço das tradições e convencionalismos, inventa a supremacia do homemmarido, decreta a subordinação da mulher-esposa; contra o casamento que pretende assegurar a igualdade de tratamento aos cônjuges e dita medidas que impede à mulher de velar pela segurança, decoro e progresso de sua família; contra o casamento que exige o beneplácito do marido para que a mulher possa trabalhar, como se o trabalho não fosse um direito e um dever de cada cidadão; contra o casamento que incentiva o parasitismo de milhares de mulheres, enquanto exige trabalho forçado de milhões de outras; contra o casamento que rouba à mãe viúva o pátrio poder dos seus filhos porque contrai novas núpcias; contra o casamento que se desmancha, que anula porque a mulher não é mais virgem; contra o casamento que justifica hipocritamente todas às limitações a capacidade da mulher em nome da unidade de direção da família, criando o consentimento da mulher para que o marido possa exercer certas atividades ligadas ao patrimônio do casal depois de declarar que a mulher possa exercer atividades do mesmo caráter, mas de importância muito menor; contra o casamento que impede a mulher casada de ser livremente tutora ou curadora como pode ser o marido, etc... etc... (Momento Feminino, 27/02/1848, p. 7).

Em virtude de tantas limitações às mulheres casadas, que para a autora não tinha nenhuma justificativa cabível, ela chamou a atenção para a necessidade imperiosa da união das mulheres na luta contra as leis limitadoras de suas liberdades individuais.

Muitas são as limitações à igualdade dos direitos da mulher em relação ao dos homens, que a lei impõe através do "estado civil". Muitas já foram as nossas conquistas, mas resta muito a conquistar nesse setor. Por isso, é nosso propósito, estudar com as leitoras nessa coluna os direitos que já temos e os que ainda havemos de ter. Porque só o trabalho das mulheres em conjunto conseguirá derrubar essa barreira de preconceitos que impede a perfeita igualdade entre os sexos e, sobretudo, a igualdade de posição da mulher e do homem na família, uma vez que os argumentos apresentados para justificar as diferenças impostas pela lei já não encontram eco no espírito e na vontade das esposas e mães de nossos dias. (Momento Feminino, 27/02/1948, p. 7).

Nice não reivindicou apenas mais direitos às mulheres casadas. Advertiu que seriam necessárias mudanças na forma como elas pensavam a si próprias e como encaravam o casamento. Portanto, defendeu que seria fundamental mudanças de mentalidade; o que nos remete a pensar que a autora sugeria mais do que mudanças sociais, defendia, ao fim e ao cabo, transformações de ordem cultural. Para ela, a conquista de direitos só seria possível quando as mulheres das camadas médias assumissem deveres e enxergassem o casamento a partir de outra ótica, não mais o percebendo como meio de subsistência. 
O que não é possível é dar mais direitos à mulher se ela continua a ver no casamento a garantia da sua subsistência e da sua estabilidade. [...] Já há as que contribuem sem gozar os direitos correspondentes, mas é necessário engrossar essas fileiras para alcançar o fim desejado. O casamento não pode mais ser encarado como solução dos problemas financeiros da mulher, porque casamento não é emprego e sim a união de duas pessoas que se dispõe lado a lado a lutar pela vida, cujo preço, caro como é, impele hoje todos ao trabalho, fonte de independência individual e de igualdade entre os homens (Momento Feminino, 18/09/1947, p. 7).

Ainda sobre as leis matrimoniais, se posicionou abertamente contra o Artigo 219, parágrafo II, da Lei $n^{\circ} 3.071 / 1916$ (Brasil, 1916, p. 133) que possibilitava a anulação do casamento em caso de "defloramento da mulher, ignorado pelo marido" (Momento Feminino, 17/10/1947, p. 5). Levando em consideração a referida lei, problematizou retoricamente: "Será de fato assim? Serão sem recato e indignas todas as mulheres que antes de se casar já tenham conhecido outro homem?"

Não. O critério de valorização da dignidade de uma mulher pela sua virgindade, longe está de corresponder a um princípio sadio de moral, e, muito menos, ao conceito de liberdade individual de nossos dias. A virgindade é um predicado físico, cuja preservação é assunto que diz respeito tão somente a quem a possui. Dignidade é um predicado moral que independe da existência da membrana virginal. Pode existir com esta e, também, independente desta. A prática do ato sexual não desonra pessoa alguma (Momento Feminino, 17/10/1947, p. 5).

Para consubstanciar seus argumentos indicou que em "países civilizados" como a França, Inglaterra e Estados Unidos, as leis já não seguiam esses princípios. Segundo ela, considerar a virgindade como elemento para a anulação de um casamento "além de uma arma perigosa contra a mulher é, sobretudo, uma humilhação que se lhe impõe em nome de um preconceito que espelha a velha concepção de atribuir absoluta liberdade ao homem e completa escravização da mulher" (Momento Feminino, 17/10/1947, p. 5). Após questionar a dupla moral sexual, prosseguiu:

A própria mulher cabe a tarefa de provar que sua dignidade tem um sentido mais alto, tem um valor menos anatômico e que se traduz na honestidade de seus sentimentos, na pureza de suas intenções, na coragem de suas atitudes e, sobretudo, na coragem de assumir a responsabilidade de seus atos. São estas e outras qualidades morais que qualificam nosso caráter de digno e honesto $e$ não, a ausência de uma membrana que a incompreensão dos homens tanto valoriza (Momento Feminino, 17/10/1947, p. 5). 
As colocações de Nice Figueiredo evidenciam uma crítica audaciosa em uma época em que a virgindade das mulheres ainda era considerada sagrada. Os discursos tradicionais evidenciavam a necessidade delas se manterem virgens até o casamento. Aquelas que ousavam desafiar essa lógica, frequentemente, ficavam estigmatizadas socialmente e sofriam discriminações tanto no âmbito familiar, quanto no mundo público. Ao contrário dos homens, que eram motivados a iniciar a vida sexual ainda muito jovens como prova de virilidade, fato que não deixava de gerar constrangimentos aos que não conseguiam desempenhar o papel masculino idealizado.

No que diz respeito ao lugar da mulher na gestão da família, Nice defendeu que era insustentável "o ponto de vista que reconhece a superioridade masculina sobre a feminina" (Momento Feminino, 07/11/1947, p. 12). Partindo desta perspectiva indagou ironicamente: "Haverá ainda justificativa para o fato de se atribuir só ao homem a chefia da família? Que vantagens resultam para a família e para cada um dos cônjuges da organização familiar?" (Momento Feminino, 07/11/1947, p. 12).

Para ambas as perguntas uma só resposta. Nenhuma. Nenhuma vantagem. Nenhuma justificativa. [...] Felizmente, chegou-se à conclusão de que os homens tem peculiaridades assim como as têm as mulheres. São diferentes, mas tanto um como outro, capazes de realizar o mesmo trabalho. Falam, eloquentemente, as fábricas, as guerras, as prisões, as artes e as letras, onde se emparelham homens e mulheres (Momento Feminino, 07/11/1947, p. 12).

Advertiu que no passado a atribuição da chefia da família ao marido se justificava pela "pretensa superioridade masculina. Superioridade intelectual, sobretudo. Por isso, o marido era o "cabeça" do casal" (Momento Feminino, 07/11/1947, p. 12). Caberia ao homem "o dever de manutenção da família e, para garantir esse dever, atribuía-lhe a superioridade econômica, quer a provinda do trabalho (muito raramente) quer a canalizada pelos dotes, heranças e todas essas insignificâncias essenciais a um bom casamento" (Momento Feminino, 07/11/1947, p. 12).

Para a autora, o fato do homem dar o sustento material à família era determinante para a divisão de tarefas: "Às mulheres os serviços domésticos dada a sua capacidade inferior, aos homens os serviços extradomiciliares, às vezes, piores que os primeiros, mas cujos resultados deveriam assegurar a manutenção da mulher no "trono domiciliar" (Momento Feminino, 07/11/1947, p. 12). Mas em sua leitura, na década de 1940, o homem de classe média já havia perdido a capacidade de manter suas mulheres em seus "tronos".

O preço caro com que a vida é vendida forçou-nos a compreender que o trabalho significa tanto o homem como a mulher e, sobretudo, ensinou que a 
divisão dos serviços para render melhor e mais, deveria ser feita segundo as aptidões de cada um e não de acordo com o sexo, como se fazia antes. Hoje, muitas mulheres e muitos homens trabalham lado a lado, superiores, iguais ou inferiores entre si, como um grupo. Hoje a família é sustentada tanto pelo marido, como pela mulher e, mais tarde, pelos filhos. Hoje, a superioridade econômica do homem é relativa $e$, por conseguinte, não lhe dá mais a superioridade intelectual. Por que, pois, fazer dele sempre o chefe? Se há necessidades de chefes, que sejam marido e mulher juntos, pois a família depende essencialmente de duas criaturas que devem ser tratadas em pé de igualdade para que "o cabeça" seja o mais capaz verdadeiramente e não aquele que se convencionou fosse o mais capaz. O convívio familiar é quem dirá qual o chefe. O que não se pode mais admitir é que, em nome de uma tradição sem fundamentos, se dê, por convencionalismo, ao homem a chefia da família (Momento Feminino, 07/11/1947, p. 12).

Destacou que era fundamental "compreender que o serviço doméstico merece uma atenção relativa, mas não pode nem deve ser a finalidade exclusiva das mulheres" (Momento Feminino, 05/12/1947, p. 2). Para ela, quando fossem removidas "as dificuldades [sobraria] tempo a toda mulher para se dedicar as atividades que assentem melhor com a sua dignidade de animal racional que, se presume, tem um cérebro pra trabalhar e produzir também" (Momento Feminino, 05/12/1947, p. 2).

Suas palavras são permeadas por certo desprezo ao trabalho doméstico, considerado improdutivo. Essa leitura assentava-se numa tradição, segundo Hannah Arendt (2007), construída na era moderna que inverteu todas as tradições que diferenciava o labor do trabalho. A diferenciação passou a glorificar o "trabalho produtivo", leia-se, aquele que produz um produto, como fonte de todos os valores. No entanto, não produziu uma única teoria que distinguisse claramente o "labor do nosso corpo" do "trabalho de nossas mãos". O que houve foi, primeiro, a distinção entre trabalho produtivo e improdutivo, e depois, um pouco mais tarde, a diferenciação entre trabalho qualificado e não-qualificado, "e finalmente sobrepondo-se a ambas por ser aparentemente de importância mais fundamental, a divisão de todas as atividades em trabalho manual e intelectual" (Arendt, 2007, p. 96).

Das três, ainda segundo Arendt, somente a distinção entre trabalho produtivo $e$ improdutivo foi a fundo na questão. A produtividade promoveu o labor ao trabalho, menosprezando, a partir do adjetivo improdutivo, os trabalhos que supostamente não enriquecem o mundo. $\mathrm{O}$ desprezo decorreu da falta de percepção de sua produtividade, pois eles não geram produtos palpáveis. Ao contrário da produtividade do trabalho, que acrescenta novos objetos ao artifício humano, a produtividade do labor só ocasionalmente produz objetos. Sua preocupação fundamental são os meios da própria reprodução. Mesmo quando sua 
reprodução já está assegurada, pode ser utilizada para a reprodução de mais um processo vital, "mas nunca produz outra coisa senão «vida»" (Arendt, 2007, p. 99).

Influenciada por essa divisão abstrata - mas cheia de sentidos práticos - entre trabalho produtivo e improdutivo, Nice Figueiredo construiu seus discursos em defesa da saída das mulheres do lar como um dos principais caminhos para a conquista da liberdade. Este discurso era direcionado especialmente às mulheres das camadas médias; a própria Nice advertiu que as mulheres pobres não tinham outra opção senão trabalhar para sobreviverem. Argumentou que o trabalho remunerado "faz bem à mente e à saúde. Dignifica e enobrece. Tempera o caráter. Ajuda viver; assegura a satisfação das nossas necessidades e classifica o indivíduo na sociedade" (Momento Feminino, 25/03/1948, p. 8). É evidente que os significados que a autora atribuiu ao trabalho podem ser relativizados a depender das condições concretas às quais são submetidas as trabalhadoras e os trabalhadores, bem como da satisfação de quem trabalha. Mas Nice estava escrevendo, primeiro, para comprovar que o Código-Civil estava defasado; depois para convencer as mulheres das camadas médias que a independência econômica era importante para a emancipação. ${ }^{13}$

Para que os empecilhos fossem eliminados seria necessário que as prerrogativas da legislação brasileira sobre a organização familiar fossem alteradas. Para ela, os dispositivos legais que regulavam o casamento eram hipócritas e contraditórios, além de contribuir para exploração de classe. Observou que os mesmos maridos que defendiam a ideia da boa organização familiar baseada na mulher dentro do ambiente doméstico, contratavam empregadas, enfermeiras e professoras, ou seja, retirava de outros lares mulheres que precisavam trabalhar. "Por acaso as cozinheiras, as lavadeiras, as professoras não têm lar? Não têm, também, uma organização familiar cujo bom desenvolvimento deve exigir sua permanência em casa?" (Momento Feminino, 25/03/1948, p. 8).

A autora se empenhou em descontruir o pensamento, muito corrente à época, de que os trabalhos domésticos eram atributos naturais do gênero feminino. Desnaturalizou a ideologia da superioridade intelectual masculina e reivindicou de maneira veemente novos lugares socioculturais para as mulheres. Defendeu uma ideia, muito cara aos comunistas da época, de que a emancipação das mulheres estava condicionada à emancipação econômica. Ao falar da classe trabalhadora o fez de maneira idealizada. Evidenciou que os valores machistas perpassavam todas as classes, mas a classe trabalhadora foi representada como mera reprodutora dos costumes burgueses, entre eles, a inferiorização da mulher. Seus textos deixam entrever que, para ela, os trabalhadores eram sempre generosos e bons. Mesmo quando defendiam que suas esposas não ingressassem no mercado de trabalho, o fazia movidos por 
uma boa intenção, influenciados por uma má formação moral orientada pela burguesia. Esta concepção estava ligada, muito provavelmente, às concepções pecebistas sobre a classe trabalhadora, vista como protagonista da revolução socialista que aspiravam, cuja vanguarda, no Brasil, caberia ao PCB. ${ }^{14}$

O artigo "A Manutenção da Família" é bastante elucidativo do que estamos dizendo. Nele, a autora analisou o modelo de família em que ao homem cabia a função de provê-la. Segundo ela, "os homens, para garantir certas vantagens [...] tomaram a si o encargo de sustentar as famílias" (Momento Feminino, 12/12/1947, p. 9). Este posicionamento implicou na formação da mentalidade das mulheres que passaram a percebê-la "como um estado natural de coisas" (Momento Feminino, 12/12/1947, p. 9).

E mesmo nas classes onde este estado natural de coisas não podia ser respeitado, porque a fome e a miséria não deixavam, não raro, o homem trabalhava desesperadamente para evitar que sua mulher concorresse com o produto do seu trabalho para o sustento da família. Havia nessa atitude dos pais, dos maridos, dos irmãos muito de boa fé e coragem, mas enormes eram os prejuízos para esses pais, maridos e irmãos e, sobretudo, para a família que queriam manter sozinhos sem a ajuda efetiva da mulher. Primeiro, o aniquilamento físico desses homens $e$ o abatimento moral que lhe seguia sempre. Depois as dificuldades que criavam para uma família onde muitas eram as bocas para comer e dois, apenas, os braços para trabalhar (Momento Feminino, 12/12/1947, p. 9).

Em sua leitura, diante da impossibilidade de os trabalhadores manterem sozinhos as suas familias, as mulheres foram impelidas ao trabalho remunerado. As mulheres pobres, antes das outras, teriam compreendido a necessidade de "cooperar financeiramente para o sustento da casa e dos filhos" (Momento Feminino, 12/12/1947, p. 9). Sem recursos, lançaram-se ao trabalho das fábricas, dos balcões e dos lares alheios. [...] Infelizmente, a lei foi sempre surda às relações familiares dessa classe, de sorte que o texto legal não se rendeu às evidencias dos fatos (Momento Feminino, 12/12/1947, p. 9).

Depois das trabalhadoras pobres, foi a vez das mulheres das camadas médias serem empurradas, por força das circunstâncias, ao trabalho. Em sua leitura, no contexto em que escrevia seus artigos, os homens desses estratos já não eram mais capazes de sustentarem suas famílias sozinhos; "e as mulheres que também não tinham dotes a oferecer, tiveram de se lançar no comércio, nos escritórios, nas repartições públicas e nas profissões liberais" (Momento Feminino, 12/12/1947, p. 9). A autora constrói uma narrativa que endossa a ideia de que naquele contexto as mulheres das camadas médias eram impelidas ao mundo do trabalho. 
No entanto, os números contrariam as expectativas da autora. De acordo com Teresa Marques e Hildete de Melo, no Brasil, até os anos 1970, a participação das mulheres no mercado de trabalho ainda era inexpressiva, apesar de crescente. Entre a década de 1940 e 1970, contexto em que o crescimento industrial no país mostrou-se mais acelerado, a taxa de atividades das mulheres acima de 10 anos registradas no mundo do trabalho permaneceu pouco significativa (em 1920 era de 13,5\%, em 1960 subiu apenas 3 pontos percentuais, atingindo 16,6\%; e em 1970 subiu para 18,5\%). ${ }^{15}$

Ainda que o aumento do número de mulheres registradas no mundo do trabalho não fosse uma realidade, Nice Figueiredo acreditava que o processo de modernização impelia ao trabalho remunerado mulheres de todas as camadas sociais e que o Código Civil estaria em descompasso com a realidade. A autora destacou que "se o dispositivo legal continuou de pé, pelo menos, muitos direitos individuais foram dados à mulher que concorria ao lado do homem para garantir a sobrevivência da família que haviam formado (Momento Feminino, 12/12/1947, p. 9). Portanto, defendeu que a lei não deveria impor exclusivamente ao homem o papel de provedor. Propôs um novo modelo de relação familiar, em que seria necessário e indispensável "repartir entre o marido e a mulher a obrigação de manter a família, em benefício da própria família e em proveito, sobretudo, dos cônjuges que, lado a lado, valorizando-se mutuamente, irão lutar para garantir a sobrevivência de um grupo que criaram juntos" (Momento Feminino, $12 / 12 / 1947$, p. 9). Para ela, a partir do trabalho, as esposas e as mães não seriam respeitadas apenas por serem esposas e mães, mas por produzirem "alguma coisa útil para o grupo familiar e para a sociedade" (Momento Feminino, 12/12/1947, p. 9); e os filhos, "esses perigosos julgadores", passariam a valorizá-las "como valorizam seus pais, criado num ambiente de ajuda recíproca, de compreensão que só a luta por um mesmo ideal pode criar" (Momento Feminino, 12/12/1947, p. 9). No que diz respeito ao trabalho doméstico, Nice observou:

As dificuldades que aparecem para uma mulher casada em relação aos filhos pequenos e à casa devem e têm de ser superadas, o primeiro com a construção de creches nos locais dos trabalhos e a última com a fabricação de material que permita a realização dos serviços caseiros com facilidade e rapidez, evitando a subordinação da mulher a tal trabalho, porque no dia em que os trabalhos domésticos forem executados mecanicamente, os homens não mais se pejarão de realizá-los também (Momento Feminino, 05/12/1947, p. 2).

Ao pensar a distribuição do trabalho doméstico e da criação dos filhos, a autora, em parte, se alinha às ideias defendidas por teóricas comunistas no que diz respeito à coletivização da criação dos filhos, mediante criação de creches nos locais de trabalho. Durante o processo da Revolução Russa de 1917, os teóricos bolcheviques - que muito influenciaram os comunistas 
brasileiros - defenderam a transferência do trabalho doméstico para a esfera pública, silenciando sobre sua divisão na esfera privada; ao contrário das feministas modernas, que defendem a redistribuição das tarefas domésticas "dentro da família", aumentando a porção do homem nas responsabilidades domésticas (Goldman, 2014). Mas ao mesmo tempo em que defendeu a coletivização do trabalho doméstico, Nice Figueiredo não deixou de demarcar que enquanto ela não fosse uma realidade, os homens deveriam dividir as tarefas com as mulheres. Para ela, a mecanização das atividades do lar era necessária para facilitar a divisão, mas enquanto não acontecesse, "tanto o homem como a mulher podem executar as duas espécies de trabalho, quer doméstico ou não doméstico, pois assim como existem as médicas, advogadas, professoras e funcionárias, existem também os cozinheiros, [ilegível], criados de quarto, criados de sala etc." (Momento Feminino, 09/07/1948, p. 5).

Não era comum ao debate feminista do contexto enfatizar que os homens deveriam compartilhar com as mulheres os afazeres domésticos. No máximo, especialmente entre as comunistas, reivindicava-se a sua coletivização, em consonância com o que foi defendido pelos bolcheviques. Observamos, portanto, que as propostas de Nice Figueiredo, em alguma medida, distanciavam-se da linha editorial de Momento Feminino. No que diz respeito às representações relacionadas ao lugar das mulheres na sociedade, muitas vezes, o jornal reforçou os ideais de feminilidade culturalmente construídos. O artigo "A luta cotidiana das mulheres" é um exemplo. Nele, as mulheres foram descritas, sem nenhuma problematização, como "heroínas do cotidiano" pelo fato de serem responsáveis por "todas as responsabilidades domésticas e da criação dos filhos" (Momento Feminino, 25/07/1947, p. 9).

Heroínas obscuras, combatentes corajosas na luta cotidiana pelo pão, pela casa, pela felicidade doméstica, as mulheres do Brasil querem, como todas as mulheres do mundo, o direito humano à alegria. Dona de casa, heroína humilde das mesquinhas tarefas sem brilho, realizadora de silenciosos milagres diários! É ela que cuida do conforto, da segurança, da felicidade do lar. É a que prepara, com as próprias mãos, o futuro dos filhos. A que conhece a tortura das filas, a falta d'água, as indignas exigências do câmbio negro, a exploração inescrupulosa, as dificuldades para conseguir o pão, o leite, a carne, os gêneros indispensáveis ao consumo da casa. [...] A que trabalha o dia inteiro e não tem horário para o repouso, nem folga, nem férias. A que dorme mal à noite preocupada com os duros problemas, a que tem um número maior de deveres do que de direitos. A dona de casa já vai adquirindo a consciência de que deve formar, com todas as outras mulheres, uma frente única de combate à crise, à falta de habitação e transportes, ao câmbio negro, às filas, à sonegação dos gêneros de primeira necessidade; uma frente única para a sua família, de um futuro mais digno para as suas crianças (Momento Feminino, 25/07/1947, p. 9).

Após destacar os problemas das donas de casa, o texto fez referência à situação das mulheres operárias e camponesas. 
Nas fábricas, nas oficinas, nas usinas, ao lado do homem, seu companheiro de lutas, a operária movimenta a força de produção. Trabalha oito e mais horas por dia, quase que num total desconforto, preparando a riqueza da nação. Viaja de madrugada nos trens de subúrbio superlotados, nos bondes morosos e cheios. Alimenta-se mal $e$ apressadamente e nem sempre pode trabalhar tranquila, com o pensamento nos filhos sem creches, sem escolas, sem hospitais. De volta à casa, ainda tem que cuidar dos arranjos domésticos e preparar comida para a família. [...] Também elas começam a sentir que devem unir-se às outras mulheres para conseguirem estabilidade no emprego, férias de um mês, acesso rápido e garantido na carreira, melhores condições de vida, barateamento dos artigos indispensáveis, o direito de serem respeitadas, clima de segurança e democracia que possam viver, constituir seus lares e criar seus filhos. [...] Nos campos e nas fazendas, a mulher vive ainda em condições primárias, no duro trabalho de sol a sol, no desconhecimento do uso do calçado, morando em choupanas miseráveis, mantida numa total ignorância, muitas vezes sem saber sequer o que se passa na cidade mais próxima. Seus filhos nascem sem a menor assistência, crescem sem escolas, comendo raízes e rapadura e morrem de verminose, malária e outras doenças. Começa também ela, que é a maior vítima e a maior sacrificada, a compreender que unida às outras mulheres precisa lutar para que as terras em que vive lhes pertençam, lutar por assistência médica e hospitalar, escolas para os filhos, casas para morar e instrumentos modernos para o cultivo do campo (Momento Feminino, 25/07/1947, p. 9).

O texto evidenciou os problemas enfrentados pelas mulheres de várias camadas sociais, mas em todos os casos naturalizou-se que os trabalhos domésticos seria uma função natural das mulheres. Diferente do que propôs Nice Figueiredo, pontuou a importância dos afazeres domésticos realizados pelas donas de casa, que trabalhavam o dia inteiro sem horário para o repouso, mas não solicitou que os homens também se responsabilizassem pelas tarefas do lar. Reivindicou condições de existência mais humanas para as trabalhadoras, tanto das fábricas quanto do campo, ao mesmo tempo eximiu os homens da responsabilidade com os trabalhos domésticos. Às mulheres caberia a função de garantir a felicidade da família. Por isso, deveriam se unir "na defesa de seu país, de seu lar e de seus filhos" (Momento Feminino, 25/07/1947, p. 9). Este discurso ratificava a violência simbólica na medida em restringe a liberdade e a autonomia, pois converteram uma relação de diferença em desigualdade (Soihet, 1997). O artigo estimulava a ideologia de que caberia às mulheres a responsabilidade total do bem-estar da família, mesmo quando elas também trabalhavam fora de casa. Na prática, este tipo de ideologia contribuiu para que a maioria das mulheres assumisse - e assume - sozinha uma série de responsabilidades na esfera doméstica, sobrecarregando-se de trabalho, ao mesmo tempo em que se sentia - se sente - culpada e deprimida quando não conseguia se enquadrar aos ideais da femilidade perfeita, que inclui o casamento, a família e a maternidade como suas principais realizações. 
Enquanto Nice Figueiredo propunha a quebra dessa lógica, o artigo do editorial colaborava para a sua permanência. O desacordo entre ela e parte das mulheres do PCB fica mais evidente no texto intitulado "Uma lição aprendida com a experiência". Em uma mesaredonda ocorrida em outubro de 1949 na sede da Associação Brasileira de Imprensa, no Rio de Janeiro, para discutir as pretensões das mulheres brasileiras e quais direitos queriam conquistar, mostrou que "as participantes divergiam quais seriam as verdadeiras conquistas femininas" (Momento Feminino, 30/10/1949, p. 9). No evento, uma oradora afirmou, em consonância com o que era defendido pelo PCB, que "as reivindicações no sentido de 'deserdação da mulher', da 'capacidade de escolher o domicílio', de 'aceitar mandato', e outros, se afastam das verdadeiras reivindicações femininas que são muito mais prementes, como os problemas das mulheres do morro, da água, da luz, da vida cara" (Momento Feminino, 30/10/1949, p. 9).

Nice Figueiredo se contrapôs a esta visão. Para ela, "se as mulheres a adotarem, limitarão muito o seu campo de ação" (Momento Feminino, 30/10/1949, p. 9). Salientou que após as conquistas das "necessidades físicas e imediatas", consideradas essenciais, as mulheres mereciam "um futuro maior e mais alto que o de morar em morros, lavar roupas com abundância de água e cozer sob clara e boa luz elétrica" (Momento Feminino, 30/10/1949, p. 9). Advertiu, ainda, que ao lado das trabalhadoras pobres havia outras "que por causalidade de nascimento não têm os mesmos problemas, que já estão em condições físicas e sociais mais favoráveis e adiantadas" (Momento Feminino, 30/10/1949, p. 9). Estas tinham a liberdade "de lutar por outros direitos que nem elas, nem as primeiras possuem ainda" (Momento Feminino, 30/10/1949, p. 9). Após as considerações declarou que, de fato, as mulheres deveriam concentrar maiores esforços para as conquistas materiais, no entanto, não poderiam descuidar das demandas daquelas que não enfrentavam esse tipo de dificuldade.

Que sejam compensados primeiro as que mais sofrem, não há dúvida. Que os nossos esforços consigam o maior bem-estar para as mulheres que mais trabalham e carregam os fardos maiores. [...] Mas daí a afirmar que as campanhas femininas devem ter só este objetivo está errado. Está errado porque vai contra a lógica e contra as próprias mulheres, impedindo que elas aspirem posições mais altas. (Momento Feminino, 30/10/1949, p. 9).

Em 1950 as divergências entre ela e a diretoria de Momento Feminino se tornaram irreconciliáveis. ${ }^{16}$ Seu posicionamento parecia radical demais para o projeto do jornal. A advogada, aparentemente aborrecida, se viu obrigada a saltar fora em 1950. O estopim se deu quando ela resolveu escrever sobre o direito de greve, a partir de 24 de fevereiro de 1950. Em todos os textos em que abordou a temática defendeu o pleno direito à greve, pensando a importância da participação das mulheres nos movimentos grevistas. Até aí, nada que 
aparentemente contrariasse os princípios comunistas, não fosse a implicância com o título Greve justa - Greve injusta, que Nice atribuiu a um dos seus textos, publicado em 17 de março de 1950. Seu objetivo era criticar as determinações legais que proibia os trabalhadores $e$ as trabalhadoras de atividades profissionais fundamentais de entrarem em greve. (Momento Feminino, 17/03/1950, p. 10). O problema é que a lei considerava praticamente todas as atividades como fundamentais. Para Nice, a restrição era um ataque à classe trabalhadora pois a greve seria um importante meio coletivo que a classe dispunha "para expressar as suas reivindicações e obter direta ou indiretamente, o cumprimento das obrigações que para com ele tenha o empregador ou terceiros" (Momento Feminino, 24/02/1950, p. 6).

A expressão "greve injusta", ao que parece, foi alvo de muitas críticas. Além disso, questionou-se se seria apropriado a discussão sobre greve em um jornal de mulheres. Diante das implicâncias, os dois últimos textos de Nice Figueiredo foram mais ácidos. Aparentemente, a advogada se impacientou com certa constância de deturpação do que escrevia. No primeiro, respondeu à crítica a expressão "greve injusta", afirmando que não havia como mascarar o nome que aparece na letra da lei e que isso não significava, necessariamente, que ela considerava alguma greve injusta (Momento Feminino, 18/05/1950, p. 10). Por fim, em 15 de junho de 1950, escreveu um pequeno texto dedicado apenas a corrigir erros da edição anterior, que comprometiam o entendimento do conteúdo, chegando mesmo a deturpá-lo. Visivelmente irritada, a colunista escreveu: "Tudo está contribuindo para que voltemos a abordar a questão "greve justa e greve injusta". Com esta, é a terceira crônica que escrevemos sobre o mesmo assunto" (Momento Feminino, 15/06/1950, p. 10). Este foi o texto que marcou a despedida da advogada. A partir de então seu nome desapareceu do jornal e a coluna "Direitos da Mulher" declinou consideravelmente. Deixou de ser regular, passando a ser publicada esporadicamente; e nós perdemos o rastro de Nice, inclusive em outros periódicos.

Quando comparamos os textos de Nice Figueiredo com a maioria das matérias publicadas em Momento Feminino, somos tentadas a cair na tentação de contrariar o pensamento da ciência histórica com a afirmação de que Nice estava à frente do seu tempo. No entanto, ela não foi a única do grupo a questionar os papéis sociais e culturais atribuídos às mulheres. No próprio jornal encontramos outras vozes que propunham novos modelos de relações de gênero. A colaboradora Maria Guerra, por exemplo, evidenciou que meninos e meninas eram educadas de maneira diferente, elemento que criava assimetrias sexuais, muitas vezes, descritas como naturais. No entanto, para a autora, as desigualdades não eram naturais mais culturalmente construídas. Portanto, segundo ela, uma das medidas centras para acabar com as desigualdades entre os sexos seria educar as crianças, independente do sexo, dentro de 
um espírito coletivo, cuja preocupação fosse formar "cidadãos e não homens e mulheres aos quais apresentamos exigências morais completamente diversas" (Momento Feminino, 0911/1954, p. 10-11).

Para além do jornal, outras mulheres, inclusive diretamente ligadas ao $\mathrm{PCB}$, também contrariaram as ideias hegemônicas do partido, ao destacar que os problemas das mulheres eram uma "questão de sexo"17 não de classe, evidenciando a lógica cultural que criava hierarquias entre os sexos. Alina Leite Paim (1919-2011) e Jacinta Passos Amado são exemplos; ambas fizeram da arte literária meios de reivindicação da liberdade das mulheres, questionando a cultura que inferiorizava o feminino.

A luta por direitos envolveu o questionamento de uma cultura misógina que tentava circunscrever as mulheres ao lar, mesmo quando era necessário que elas saíssem para trabalhar. No Brasil, guardadas as devidas proporções e as diferenças concretas das experiências, mulheres de todas as raças, classes e credos tiveram e ainda têm suas experiências marcadas pelo machismo que inúmeras vezes se expressa de maneira brutal e assassina. Antes da década de 1970, considerada "A Década" do feminismo no Brasil, feministas brasileiras de variados grupos já alertavam para a necessidade de romper com essa lógica. Elas insistentemente disputaram os espaços públicos para impor suas demandas e defender a utopia de um mundo sem desigualdades entre homens e mulheres. Na década de 1990 Margareth Rago (1996) chamou a atenção para o impacto que lhe causou a escrita feminina/ista da anarquista Maria Lacerda de Moura (1887-1945). Naquele momento se acreditava que a desconstrução do discurso médico definidor da identidade feminina era obra da atualidade. Não era. Maria Lacerda, na década de 1920, se posicionou diametralmente contrária aos saberes científicos misóginos sobre as relações amorosas e sexuais. "Colocando-se ao lado dos pensadores que defendiam a educação sexual $e$ a emancipação das mulheres, ela propunha uma nova moral sexual de cunho profundamente libertário" (Rago, 1996, p. 107). ${ }^{18}$

Ao longo da primeira metade do século XX a "questão sexual" e o questionamento de uma dupla moral para os gêneros animaram o debate. O movimento não foi homogêneo, especialmente no que diz respeito ao tema da liberdade sexual. Entre as femininas anarquistas e comunistas, houve uma crítica contundente ao duplo padrão moral da sociedade. Na década de 1920, Maria Lacerda de Moura "antecipou" o que seria o grande centro de investimento do movimento feminista da década de 1970, a saber, a questão dos direitos de reprodução e da violência doméstica. (Rago, 2007). Na década de 1930 foi a vez de Patrícia Galvão, mais conhecida como Pagu, "antecipar" o debate caro à década de 1980. No romance Parque Industrial, publicado em 1933 (assinado com o pseudônimo de Mara Lobo, "antecipou" uma 
crítica levantada mais fortemente no movimento feminista brasileiro na década de 1980, qual seja, a exploração de classe presente entre as mulheres, demonstrando que os sujeitos são atravessados por várias identidades que se sobrepõem (Alves, 2017).

Na década de 1940, como demonstramos, parte das colaboradoras de Momento Feminino, entre elas Nice Figueiredo, "antecipou" o debate acerca da dupla moral sexual e das diferenças culturais que marcavam a construção do "ser homem" e "ser mulher". Neste mesmo período e avançando para as décadas de 1960-70, Alina Leite Paim e Jacinta Passos Amado também resolveram se "antecipar" na denúncia contra a dupla moral sexual; alertando que as mulheres também tinham direito ao prazer sexual, inclusive à masturbação (Alves, 2017). Ainda que dentro da heteronormatividade e de uma visão biológica dos sexos, ${ }^{19}$ elas reivindicaram novos modelos de casamento $e$ analisaram as especificidades de ser mulher dentro das diferenças (trabalhadoras, intelectuais, ricas e pobres).

Além das comunistas, a década de 1960 no Brasil também foi marcada por práticas feministas, apesar do autoritarismo, conservadorismo e violência de uma ditadura civil-militar que durou 21 anos (1964-1985). Naquela década, até os primeiros anos da seguinte, as feministas criaram grupos de reflexão feministas, atuaram na imprensa, na Igreja, nas universidades e na literatura. Mulheres como Heleihet Saffioti, Carmen da Silva, Rose Marie Muraro, Heloneida Studart, Romi Medeiros, Ecilda Ramos de Souza, Ana Montenegro, Alina Paim, entre tantas outras que ainda desconhecemos desenvolveram atividades e leituras feministas da realidade (Pedro, 2006; Duarte, 2005; Méndez, 2008). Diante de tantas mulheres que resolveram se "antecipar" ao atribuído quase que exclusivamente ao movimento feminista da década de 1970 fica difícil sustentar que as mulheres que precederam esse movimento, apesar das ditaduras que impunham perseguição, vigilância e censura, se recolheram para esperar a tempestade passar e só depois retomarem suas lutas por liberdade. Acreditamos que o movimento foi além das ondas. Jogando com as possibilidades de cada contexto, elas surfaram como puderam.

\section{Referências}

A LUTA cotidiana das mulheres. Momento Femininc, Rio de Janeiro, 25 jul. 1947. p. 9.

ALVES, Iracélli da Cruz. A política no feminino: uma história das mulheres no Partido Comunista do Brasil seção Bahia (1942-1949). Dissertação (Mestrado em História). Feira de Santana, Universidade Estadual de Feira de Santana, 2015. 
ALVES, Iracélli da Cruz. Os movimentos feminista e comunista no Brasil: história e historiografia. Tempos Históricos, Marechal Cândido Rondon, v. 21, n. 2, jun./dez., 2017, p. 107-140.

ARENDT, Hannah. O labor de nosso corpo e o trabalho de nossas mãos. In: $A$ condição humana. $10^{a}$ ed. Rio de Janeiro: Forense Universitária, 2007, p. 90-104.

ATENDENDO a sua consulta. Momento Feminino, Rio de Janeiro, ano 1, n. 16, 07 nov., 1947, p. 12.

BRASIL. Lei no 3.071, de $1^{\circ}$ de janeiro de 1916. Código Civil dos Estados Unidos do Brasil. Rio de Janeiro, DF: Presidência da República [1916]. Disponível em: < http://www2.camara.leg.br/legin/fed/lei/1910-1919/lei3071-1-janeiro-1916-397989-publicacaooriginal-1-pl.html> Acesso em: 31 jun., 2019.

CARNEIRO, Sueli. Identidade feminina. In: SAFFIOTI, Heleieth I. B; MUÑOZ-VARGAS, Monica (orgs.). Mulher brasileira é assim. Rio de Janeiro: Rosa dos Tempos, 1994.

CARNEIRO, Sueli. Mulheres em movimento. Estudos Avançados, São Paulo, v. 17, n. 49, 2003, p. 117-132.

CONGRESSO Nacional. Momento Feminino, Rio de Janeiro, ano 3, n. 60, 30 jun., 1949, p. 5.

DAVIS, Angela. Mulheres, raça e classe. São Paulo: Boitempo, 2016.

DIAS, Maria Olila Leite da Silva. Quotidiano e Poder em São Paulo no século XIX. 2 ed. São Paulo: Brasiliense, 1995.

DUARTE, Ana Rita Fontes. Carmen da Silva: o feminismo na imprensa brasileira. Fortaleza: Expressão Gráfica e Editora, 2005

FACULDADE Nacional de Direito (nota de convocação). Correio da Manhâ, Rio de Janeiro, ano 40, n. 14214, 07 mar., 1941, p. 8.

FIGUEIREDO, Nice. Casamento não é emprego. Momento Femininc, Rio de Janeiro, 18 set., 1947. p. 7

FIGUEIREDO, Nice. A anulação do casamento. Momento Femininc, Rio de Janeiro, 17 out. 1947. p. 5

FIGUEIREDO, Nice. A capacidade da mulher casada. Momento Feminino, Rio de Janeiro, ano 1, n. 30, 20 fev., 1948, p. 4.

FIGUEIREDO, Nice. A manutenção da família. Momento Feminino, Rio de Janeiro, 12 dez. 1947. p. 9. 
FIGUEIREDO, Nice. A mulher casada e o trabalho. Momento Femininc, Rio de Janeiro, 05 dez. 1947. p. 2.

FIGUEIREDO, Nice. Contra o casamento. Momento Feminino, Rio de Janeiro, ano 1, n. 31, 27 fev., 1948, p. 8.

FIGUEIREDO, Nice. É preciso compreender... Momento Femininc, Rio de Janeiro, ano 1, n. 13, 14 nov., 1947, p. 12.

FIGUEIREDO, Nice. Greve justa - greve injusta. Momento Feminino, Rio de Janeiro, ano 3, n. 66, 17 mar. 1950, p. 10.

FIGUEIREDO, Nice. Mulheres versus Homens. Momento Feminino, Rio de Janeiro, ano 1, n. 36, 09 abr., 1948, p. 5.

FIGUEIREDO, Nice. O “Estado Civil” das Mulheres. Momento Feminino, Rio de Janeiro, 12 set. 1947. p. 7

FIGUEIREDO, Nice. O chefe da família. Momento Feminino, Rio de Janeiro, 07 nov. 1947. p. 12.

FIGUEIREDO, Nice. O direito de greve. Momento Feminino, Rio de Janeiro, ano 3, n. 65, 24 fev., 1950, p. 6.

FIGUEIREDO, Nice. O estado civil das mulheres. Momento Feminino, Rio de Janeiro, ano 1, n. 8, p. 7, 12 set., 1947.

FIGUEIREDO, Nice. Os deveres da mulher casada. Momento Feminino, Rio de Janeiro, ano 1, n. 27, 23 jan., 1948 , p. 8.

FIGUEIREDO, Nice. Um erro de revisão, Momento Femininc, Rio de Janeiro, ano 4, n. 70, 15 jun. 1950, p. 10.

FIGUEIREDO, Nice. Uma lição aprendida com a experiência. Momento Feminino, Rio de Janeiro, 30 out. 1949. p. 4.

FIGUEIREDO, Nice. Você não trabalha porque não quer. Momento Femininc, Rio de Janeiro, 09 jul., 1948. p. 5.

FIGUEIREDO, Nice. Você quer trabalhar? Momento Feminino, Rio de Janeiro, ano 1, n. 34, 25 mar., 1948, p. 8.

GUERRA, Maria. Educação para a guerra, educação para a paz. Momento Feminino, Rio de Janeiro, ano 7, n. 108, set./out./nov., 1954, p. 10-1. 
GOLDMAN, Wendy Z. Mulher, Estado e Revolução: política familiar e vida social soviéticas, 1917-1936. São Paulo: Boitempo, 2014

JEAN, Yvone. Momento Feminino. Diário de Notícias, Rio de Janeiro, ano 17, n. 7606, 12 ago. 1947. Presença da Mulher, p. 3 (Segunda Seção).

LOBO, Mara. Parque Industriai. Rio de janeiro: José Olympio, 2006.

MACEDO, Elza Dely Velos. Ordem na casa e vamos à luta! Movimentos de mulheres: Rio de Janeiro (19451964). Tese (Doutorado em História). Rio de Janeiro: Universidade Federal Fluminense, 2001.

MELLO, Maria Tereza Chaves de. A Modernidade Republicana. Tempo, Rio de Janeiro, n. 26, 2008, p. 15-31.

MOTTA, Rodrigo Patto Sá. Em guarda contra o perigo vermelho: o anticomunismo no Brasil (1917-1964). São Paulo: Perspectiva/FAPESP, 2002.

MÉNDEZ, Natália Pietra. Com a palavra o segundo sexo: percursos do pensamento intelectual feminista no Brasil dos anos 1960. Tese (Doutorado em História). Porto Alegre: Universidade Federal do Rio Grande do Sul, 2008.

PEDRO, Joana. Narrativas fundadoras do feminismo: poderes e conflitos. Revista Brasileira de História, São Paulo, v. 26, n. 52, 2006, p. 249-272.

RAGO, Margareth. O prazer no casamento. Cadernos Ceru, série 2, n. 7, 1996, p. 97-111.

RAGO, Margareth. Entre a História e a liberdade: Luce Fabri e o anarquismo contemporâneo. São Paulo: UNESP, 2001, p. 219.

RAGO, Margareth. Ética, anarquia e revolução em Maria Lacerda de Moura. In: FERREIRA, Jorge; REIS, Daniel Arão (orgs.). A formação das tradições (1889-1945). v. 1. Rio de Janeiro: Civilização Brasileira, 2007.

SOIHET, Rachel. Feminismos e antifeminismos: mulheres e suas lutas pela conquista da cidadania plena. Rio de janeiro: 7Letras, 2013.

SOIHET, Rachel. Violência simbólica: saberemos masculinos e representações femininas. Estudos Feministas, Santa Catarina, v. 5, n. 1, 1997, p. 7-30.

SOIHET, Rachel. Condição feminina e formas de violência: mulheres pobres e ordem urbana, 1890-1920. Rio de Janeiro: Forense Universitária, 1989. 
TORRES, Juliana Dela. A representação visual da mulher na imprensa comunista brasileira (1945-1957). 2009.

Dissertação (Mestrado em História). Londrina: Universidade Estadual de Londrina, 2009.

VIANNA, Marly de Almeida Gomes. Revolucionários de 1935: sonho e realidade. São Paulo: Expressão Popular, 2007.

VIEIRA, Cláudia Andrade. História das mulheres: feminismo e política na Bahia. Simões Filho: Calango, 2015.

\begin{abstract}
${ }^{1}$ Momento Feminino circulou ininterruptamente como semanário até o seu $28^{\circ}$ número, publicado em 30 de janeiro de 1948. O n. 29 só ganhou as ruas no dia 13 de fevereiro, ou seja, quatorze dias depois. Após o intervalo, voltou a circular semanalmente até o dia 12 de março. Houve mais um intervalo quinzenal e a edição seguinte só saiu no dia 25 , quando o jornal retomou a regularidade semanal, interrompida na $40^{\mathrm{a}}$ edição publicada em 07 de maio. Após esta edição, voltou a circular em 11 de junho, seguindo suas publicações semanais até o dia 25, quando assumiu a regularidade quinzenal, com algumas interrupções. Em 1949 saiu mensalmente até março, quando foram publicadas duas edições: uma no dia 06 e outra no dia 25.

${ }^{2}$ Em 1952 a revista só circulou mensalmente nas duas primeiras edições do ano, que circularam em janeiro $e$ fevereiro. A edição seguinte saiu em abril conjugada ao mês de março. Em junho e julho manteve a regularidade mensal interrompida a partir de agosto, já que os dois números seguintes saíram bimestralmente. No último mês do ano saiu a edição especial de natal. A partir de 1953 os intervalos de publicação foram mais largos. Entre janeiro $e$ abril circulou bimestralmente. $\mathrm{O}$ número seguinte só circulou em julho, conjugando os meses de maio e junho. $\mathrm{O}$ último número saiu às ruas em novembro como outubro-novembro acompanhado do suplemento de natal, programado para o mês de dezembro. No ano seguinte, o número 103 circulou como janeiro/fevereiro. Entre março $e$ abril voltou a ser mensal. Os números 104, 105 e 106 saíram de forma conjugada; maio/junho, julho/agosto, setembro/outubro/novembro, respectivamente.
\end{abstract}

3 As edições de Momento Feminino estão armazenadas na Hemeroteca Digital da Biblioteca Nacional https://bndigital.bn.gov.br/hemeroteca-digital. Nos dois últimos anos não conseguimos precisar a regularidade, em função dos limites do próprio arquivo, que aparentemente não armazena alguns números. Entre as edições de 1955 encontramos apenas os números 109 a 112 e 115. Em 1956, provavelmente o último ano do jornal, a hemeroteca armazena apenas as edições 116 e 118, portanto falta a 117 e não sabemos se após a 118 circulou alguma que se perdeu no tempo.

${ }^{4} \mathrm{O}$ número de páginas tendia a aumentar em momentos especiais, a exemplo de datas festivas como o Dia Internacional da Mulher, Dia das mães e natal; ou diminuir nas fases em que os problemas financeiros tornavam-se mais graves. Diferente do que era comum aos jornais, não trazia reportagens desde a primeira página.

${ }^{5}$ Em sua dissertação sobre a iconografia de Momento Feminino, Juliana Torres analisa as capas que geralmente traziam imagens destacadas (TORRES, 2009, p. 73). Elza Macedo (2001), em sua tese de doutorado, apresenta informações sobre o formato, estrutura e apresentação do jornal.

${ }^{6}$ Liderada por Bertha Lutz (1894-1976), a organização foi oficialmente inaugurada em 09 de agosto de 1922. Teve como questão central, mas não única, a incorporação da mulher como sujeito portador de direitos políticos. Organização de nível nacional, alcançou uma institucionalização surpreendente. Surgiram filiais da FBPF em vários Estados brasileiros, como São Paulo, Bahia e Pernambuco, assim como outras associações assistenciais e profissionais se uniram à entidade. (PINTO, 2003; SOIHET, 2013).

${ }^{7}$ Os cargos de direção mantinham alguma rotatividade e não sabemos se todas as mulheres que fizeram parte deles eram do partido, mas a direção geral, da primeira à última edição, coube a Arcelina Mochel, que durante todo o período foi militante do PCB. ${ }^{7}$

${ }^{8} \mathrm{O}$ anticomunismo, segundo Rodrigo Patto Sá Motta (2002), é um corpo heterogêneo cujo único ponto de união é a recusa ao comunismo. No Brasil, surgiu logo após a Revolução Russa de 1917 e foi protagonizado por grupos de orientação conservadora, passando por momentos de maior e menor intensidade. De acordo com Motta, os períodos de maior ofensiva anticomunista foram: 1935 até 1937 (culminou no golpe que deu início a ditadura do Estado Novo até 1945); 1946-1950 (contexto marcado pela chamada Guerra Fria) e 1961-1964 (teve como resultado o Golpe militar e sua posterior ditadura, que durou até 1985). Sob forte influência do discurso católico, a temática moral ocupou lugar de relevo. As representações anticomunistas insistiam em apresentar os comunistas como destruidores da família, da moral e dos "bons costumes". "Divórcio, libertação da mulher, educação sexual e aborto, estas medidas adotadas pelos bolcheviques [após a Revolução Russa de 1917] serviam para conferir verossimilhança às afirmações de que o comunismo visava a destruição da família e a solapar a moral" (MOTTA, 2002, p. 66). 
${ }^{9}$ Teresa Cristina Marques e Hildete de Melo (2008) analisam pormenores importantes acerca das disputas políticas em torno do Código-Civil, evidenciando desde a militância da FBPF na década de 1930, passando pela atuação parlamentar de Bertha Lutz entre 1936 e 1937, que também era presidenta da federação, até a atuação, nas décadas de 1940-50, do então deputado federal Nelson Carneiro e do senador Mozart Lago, ambos partidários de mudanças que liberassem as mulheres casadas. As autoras também evidenciam o protagonismo de duas importantes advogadas feministas: Romy Martins Medeiros da Fonseca e Orminda Ribeiro Bastos, responsáveis pela escrita do texto preliminar do projeto de lei do senador Mozart Lago, apresentado em 1952, relativo a refutação da incapacidade jurídica das mulheres casadas.

${ }^{10}$ Vestir os nus narra uma história envolvendo a tentativa de suicídio de uma mulher, Ersília. O fato é narrado através de várias versões dos personagens envolvidos e do próprio espectador.

${ }^{11}$ Os textos estão assim distribuídos: doze em 1947, vinte e sete em 1948, cinco em 1949 e sete em 1950.

12 Observemos que ironia usada fazia referência a um ditado muito comum entre os homens acostumados a dizer que "a vida de solteiro é melhor que a de casado". Aliás, estas representações ainda são correntes hoje. Não é incomum, por exemplo, nas festas de casamento os homens usaram camisas com estampas em que o noivo aparece triste, segurando a mão de uma esposa sorridente. A imagem geralmente vem acompanhada da frase Game over, indicando que a vida de casado seria o fim de uma vida masculina feliz. Guardadas as devidas proporções, ontem e hoje, a mesma sociedade que acha graça nas piadas masculinas/machistas contrárias ao casamento, acende o alerta da "moral" e dos "bons costumes" quando a mulher ousa não querer casar ou fazer qualquer ponderação sobre a possibilidade. E Nice Figueiredo parecia ter consciência disto quando escreveu que não era contra o casamento em si, mas contra o modelo matrimonial que "diminui e inferioriza a mulher" (Momento Feminino, 27/02/1848, p. 7).

${ }^{13}$ Este discurso era direcionado especialmente às mulheres das camadas médias. Como veremos nas páginas que seguem, a própria Nice advertiu que as mulheres pobres não tinham outra opção senão trabalhar para sobreviverem. Historicamente, as experiências das mulheres das camadas populares, especialmente as mulheres negras, e as expectativas sociais sobre elas destoam em muitos níveis (casamento, família, trabalho) das experiências das mulheres ricas, brancas e de classe média. Cf. SOIHET, 1989; CARNEIRO, 1994; LEITE, 1995; CARNEIRO, 2003; DAVIS, 2016.

${ }^{14}$ O PCB foi fundado em março de 1922, período de afirmação internacional do regime socialista da então União Soviética. Em 1924, o PC brasileiro foi admitido na Internacional Comunista (IC), fundada em março de 1919 para ser a organização internacional dos comunistas. Como Seção Brasileira da IC, o PCB, em que pese as controversas sobre até que ponto seguiu ao pé da letra as orientações da IC, não seria imune as suas orientações que, em linhas gerais, defendia as teses de Lênin que só a revolução socialista livraria o mundo das mazelas do imperialismo. As táticas estabelecidas para chegar à estratégia variaram a depender da conjuntura histórica e foram adaptadas pelos partidos comunistas nos vários países (VIANNA, 2007).

${ }^{15}$ Não podemos esquecer que nem todas as mulheres trabalhadoras eram registradas pelos censos. Provavelmente, muitas mulheres que realizavam trabalhos informais (lavadeiras, cozinheiras, empregadas domésticas, trabalhadoras rurais, vendedoras ambulantes etc.) não eram contabilizadas pelos registros oficiais.

${ }^{16}$ Embora o jornal tenha feito a ressalva, continuou publicando os textos de Nice por um período. Momento Feminino pretendia-se democrático, o que explica a continuidade. Além disso, certamente entre suas diretoras havia divergências sobre o que era central no debate sobre a "questão feminina". Nice Figueiredo não foi a única articulista a defender a desconstrução dos padrões culturais de gênero. Outras autoras, com participação menos regular, também propuseram a quebra das hierarquias sexuais. A análise aparecerá de forma mais ampla na tese de doutorado, que ainda está em processo de elaboração.

17 O termo "questão" - a "questão da mulher"; a "questão do negro", a "questão do oriente" - passou a ser largamente utilizado no Ocidente a partir da segunda metade do século XIX. O Brasil mais especificamente, também abusou dessa terminologia entre o final do XIX e primeira metade do século XX (MELLO, 2008).

18 Maria Lacerda de Moura não foi a única. Novos estudos estão se impondo e revelando que o pensamento/movimento feminista da primeira metade do século $\mathrm{XX}$ foi além das reivindicações relacionadas ao acesso ao mundo da política pública, da educação formal e do trabalho. Cf. RAGO, 2007; SOIHET, 2013; VIEIRA, 2015.

${ }^{19}$ À época ainda não havia estudos que questionavam o caráter histórico e cultural da construção do sexo, tampouco o conceito de gênero existia enquanto instrumento de análise sócio-histórica. Portanto, embora questionassem a naturalização de determinadas diferenças sexuais, bem como as hierarquias construídas a partir dessas diferenças, seria anacrônico esperar que elas pensassem mulher/homem; masculino/feminino fora dos esquemas biológicos. 